\title{
Experimental Research on the Parameters of Electric Vehicles
}

\author{
R. Čech*, P. Tomčík, J. Kulhánek, R. Trojan \\ Department of Vehicle Materials and Technologies, Faculty of Metallurgy and Material Engineering, \\ VŠB -TU of Ostrava, Czech republic \\ *Corresponding author: radim.cech@vsb.cz
}

DOI: 10.2478/v10158-012-0011-6

\begin{abstract}
This paper describes the methodology and measured results obtained by monitoring the drive and electric vehicle management. It describes an application for recording functional values during the operation of The StudentCar Electric developed by the Department of Vehicle Materials and Technologies. The end of the article is devoted to the comparison of measured and generally available data.
\end{abstract}

KEY WORDS: electromobility, electric vehicle, BMS.

\section{INTRODUCTION}

Electrical power has become one of the most important parts of our everyday life. Most people take it for granted, but they do not associate it with their personal vehicles. They travel by trams, underground, trolley buses, and trains, while their cars are diesel or gasoline powered. The reason for this is twofold. Firstly, diesel fuel was cheaper and more accessible than electrical power at the turn of the $19^{\text {th }}$ and $20^{\text {th }}$ centuries. Secondly, the battery capacity was low at that time. The trend has continued for over 100 years, up to the present time. The tendency to reduce gas emissions from fossil fuels started in the 80s. This manifested itself as an increase in indirect expenses for making combustion more efficient. Even so, the efficiency of today's internal combustion engines does not exceed 35\% (Macur, 2011).

We dare say that we have reached a time when the mass use of electromobility is starting to be introduced into transportation. We are unsure why the development in electromobility is escalating so rapidly at the moment. There are clearly more factors influencing this development, for example the pervasive requirement to be eco-friendly, the decreasing supply of fossil fuels, the lobbying of the automotive industry and power engineering, the progressive development of battery technology or mass media pressure. The present time clearly favours electromobility development. The aim is to convince as many people as possible that we are going in the right direction.

\section{DVMT ACTIVITIES OF SCIENCE \& RESEARCH}

Thanks to this new trend, the Department of Vehicle Materials and Technologies at the Technical University of Ostrava (hereinafter "DVMT") has engaged in activities aimed at increasing its qualification in the area of electromobility research and development. 


\subsection{EkoCar Project}

UPTAT initiated its electromobility technology development with the pilot project EkoCar CZ.1.07/1.1.07/11.0109. As part of this project, the electric automobile StudentCar Electric was created (Figure 1). This electric car features several different approaches to electromobility.

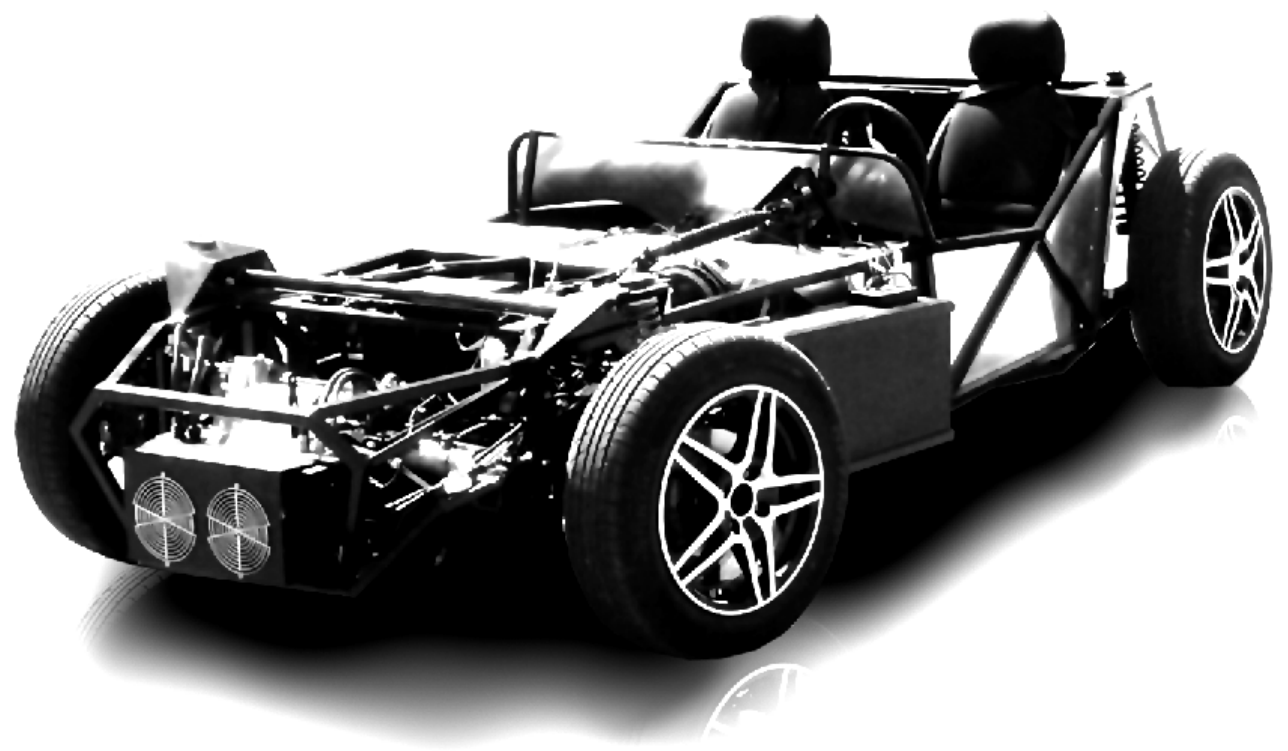

Figure 1: StudentCar Electric.

StudentCar Electric was designed as a two-seater roadster with acceleration to $100 \mathrm{~km} / \mathrm{h}$ in 8 seconds, and a top speed electronically limited to $150 \mathrm{~km} / \mathrm{h}$. The range of the vehicle is $180-260 \mathrm{~km}$, depending on the driving style. The car includes batteries with a total capacity of $27 \mathrm{kWh}$ and a nominal voltage of $270 \mathrm{~V}$. The water-cooled asynchronous motor (Figure 2) has a maximum power output of $77 \mathrm{~kW}$, torque of $190 \mathrm{Nm}$, and a frequency of rotation $12,000 \mathrm{r} / \mathrm{min}$.

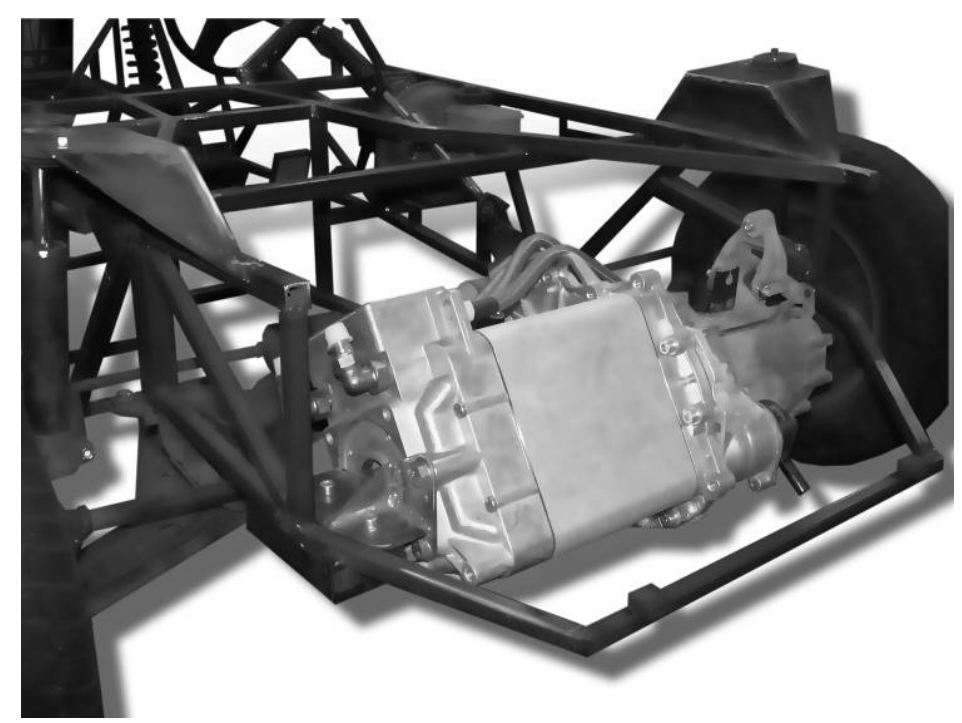

Figure 2: Asynchronous water-cooled $3 f$ motor Siemens. 
Through StudentCar Electric we wanted to demonstrate that even an electric car can meet the ambitions of a sports car. The possibility of placing individual components arbitrarily on the chassis allowed us to deliver an optimal balance of the axle and lower the vehicle's centre of gravity as low as possible to the road (Figure 3). This would be more difficult with a common car converted to an electric one.

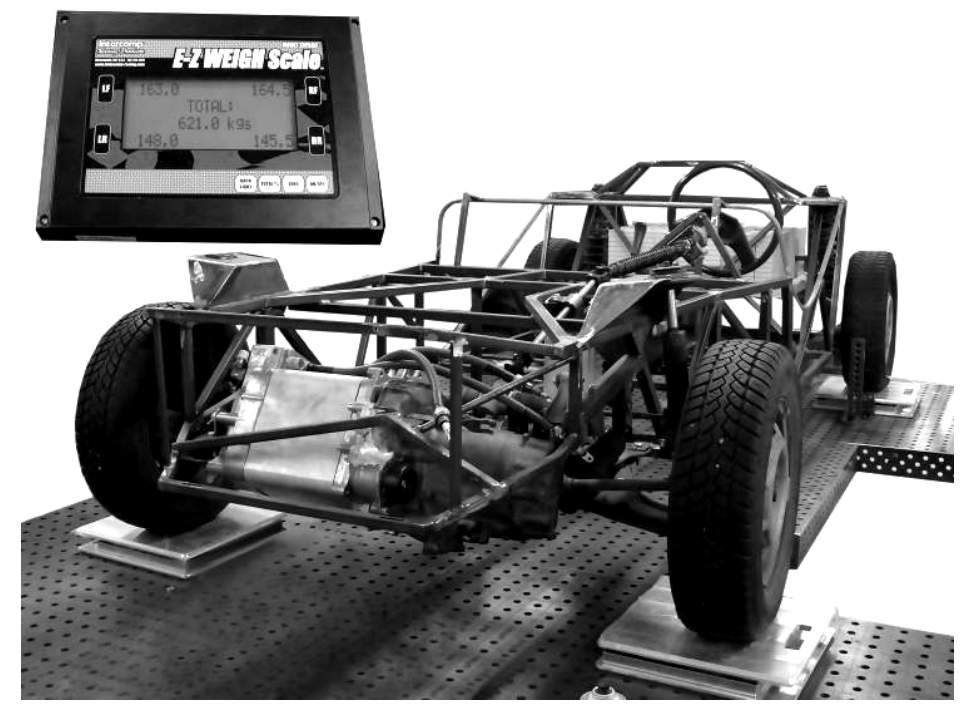

Figure 3: Illustration of how components are balanced on StudentCar Electric.

We managed to keep the vehicle's weight under $850 \mathrm{~kg}$ even with a battery weight of 300 $\mathrm{kg}$. The total weight of the vehicle is a very important factor in designing electric cars. It positively effects both consumption and range, but also vehicle characteristics, such as acceleration, top speed, and braking distance. Making the vehicle lighter is undeniably the right step, which leads to reducing the environmental burden of transport. The vehicle's weight is directly dependent on its comfort and safety. Today's modern cars must meet strict standards in both passive and active safety. Safety features increase the weight of a car by an average of $200 \mathrm{~kg}$, and comfort features, such as damping and servomotor, a further $300 \mathrm{~kg}$. This is evident, for example, in the weight difference of $405 \mathrm{~kg}$ between the first and fifth generations of VW Golf, the most common car in the EU (Plichta, 2008). It is important to develop alternative materials and seek ways to reduce the weight of car components.

\subsection{Research of Materials for Electric Vehicles}

DVMT studied alternative materials for the manufacture of functional and electrical insulation parts of the electric car. The materials were tested for breakdown field strength. Based on the newly acquired information, we are now able to choose better construction materials from the perspective of balancing electrical and mechanical properties (Čech, Buřval \& Klaus, 2011).

\subsection{Use in Education}

StudentCar Electric was designed also to be used in teaching to demonstrate individual design groups and functions of the electric car (Figure 4). 


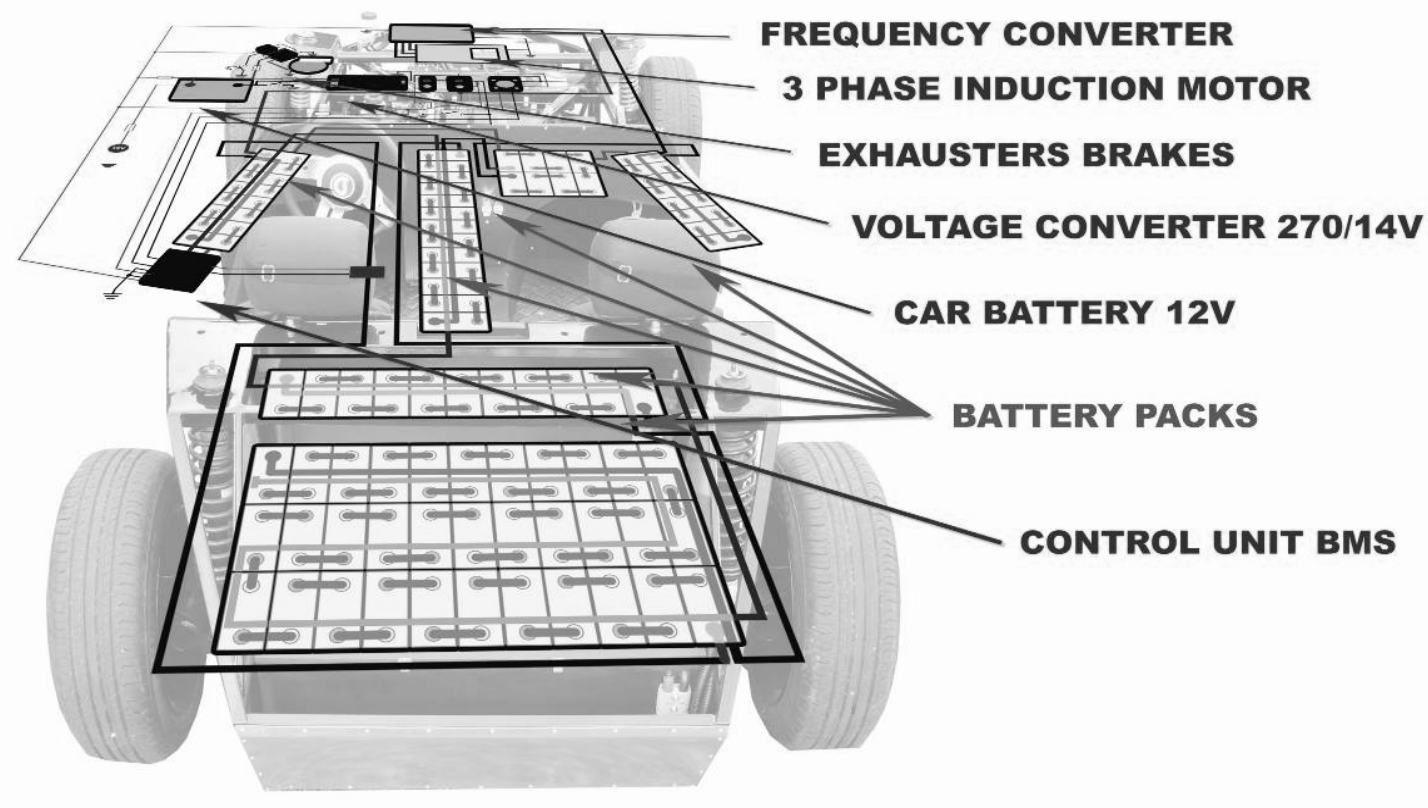

Figure 4: Components placement - StudentCar Electric.

To store energy, LiFeYPo4 traction batteries (Figure 5) were used, which are characterised particularly by a high current density. Among the advantages of these batteries are compact design, low weight, high capacity, high current values, and very low self-discharge. The downside of the batteries is the need for the use of electronic protection for the individual cells when charging and discharging. Values specified by the manufacturer must not be exceeded, else cells could be damaged. Such damage is usually irreversible, therefore when charging the batteries, parameters must be checked in real time.

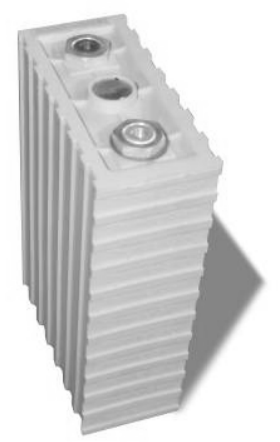

Figure 5: Battery cell LiFeYPo4 ThunderSky.

The project instigated teaching platforms to map the individual systems of the electric car. One of the platforms deals with the electronic control of the cells and the control and management of the modern traction batteries. This system is called BMS (Battery Management System). Figure 6 shows a block diagram of this system. 


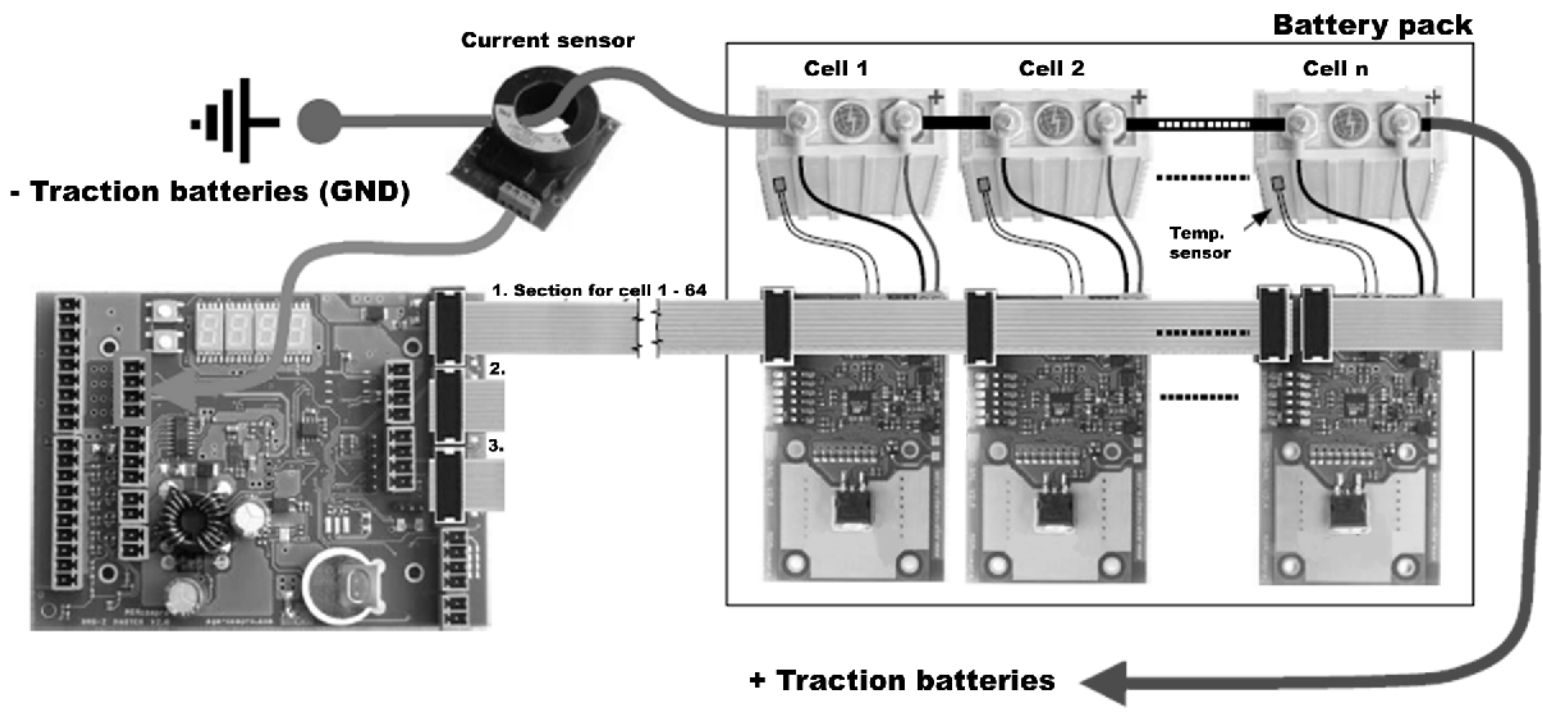

Figure 6: Battery management system.

Another training block deals with monitoring the recovery and discharge using software developed at DVMT. The software is called Controller Monitor (Figure 7) and processes the main parameters of the electric car's operation. This allows the creation of a time map of discharge, charging, and position of the accelerator, as well as the temperature of the components (e.g., traction motor) in normal operation.

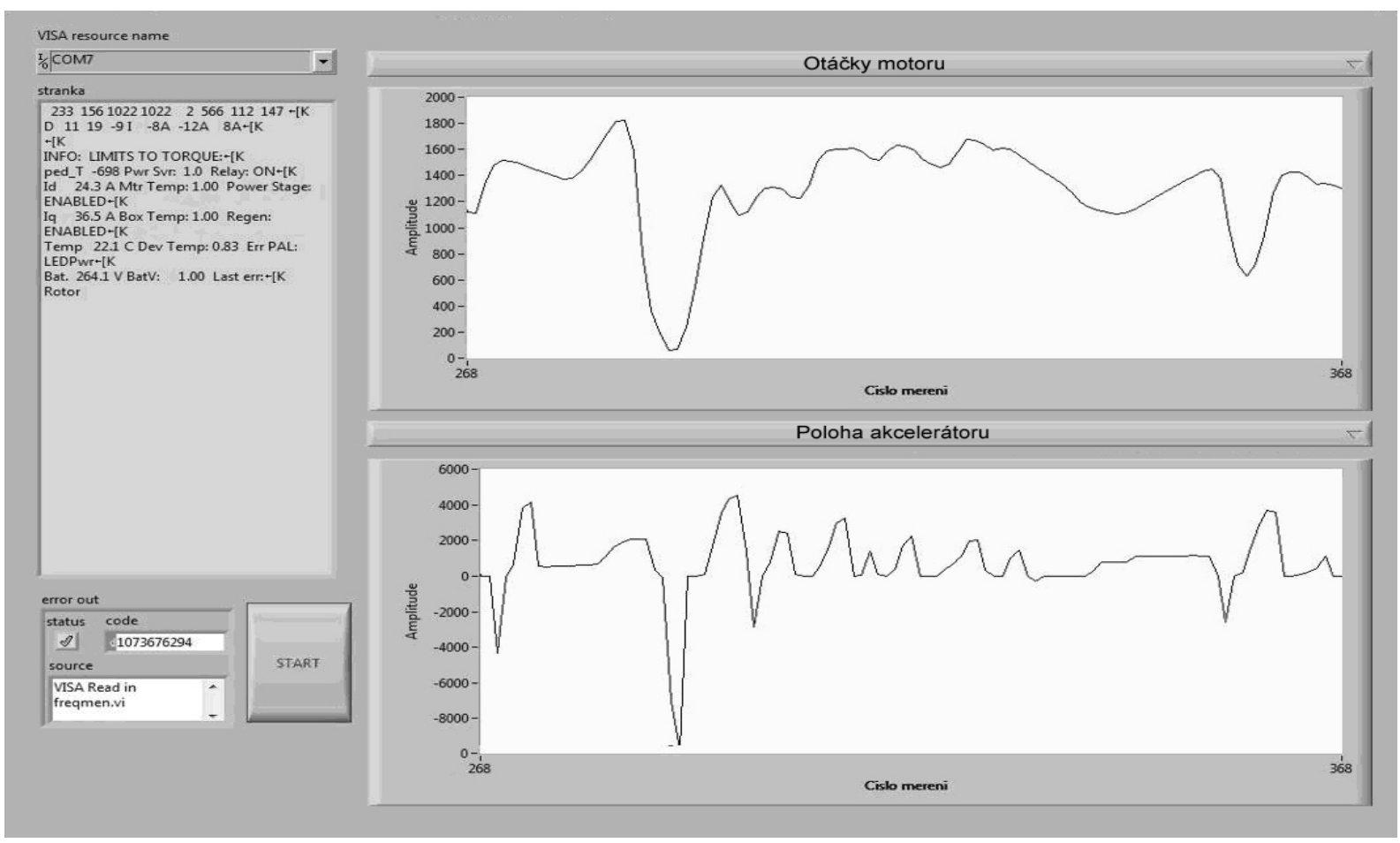

Figure 7: Controller Monitor Software. 
Through a comparison of data measured by the software, we verified the mutual relations of the measured quantities. Figures 8 and 9 illustrate how the accelerator's position depends on the current, speed, voltage, and time. These values are measured in real time in the StudentCar Electric using Controller Monitor. In the first graph (Figure 8), we can see that the position of the accelerator (thin line) is directly dependent on the current waveform (thick line). In addition, we notice an immediate response of the current to the accelerator's instruction. The current then creates proportional torque in the motor. The response of the accelerator to torque in the motor is virtually instantaneous. This is positively reflected in the operational flexibility of the car. With modern cars, the fast response of the throttle is, by contrast, partially suppressed. The start of the torque is deliberately slowed down to avoid an increase in emissions due to the rapid acceleration of the combustion engine.

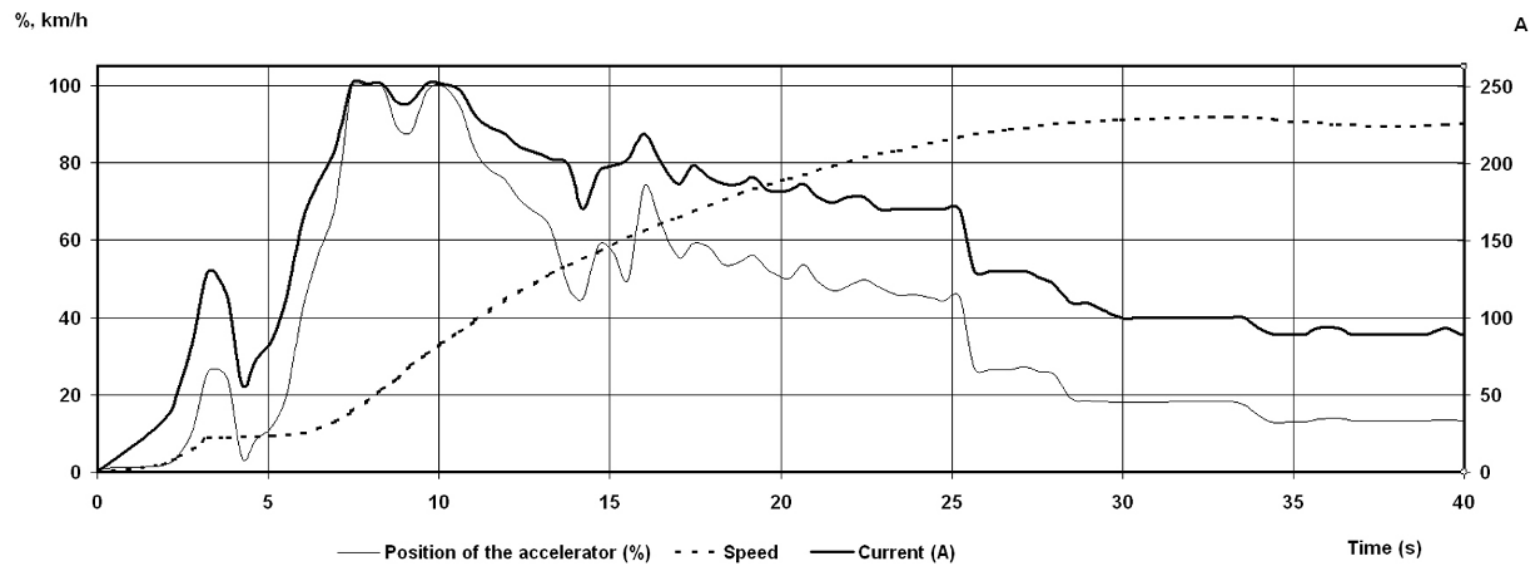

Figure 8: Electric operating values.

The second graph (Figure 9) shows the mutual relationship between the current (thick line) and voltage (thin line). At the beginning, in the range of 0-5 seconds, it is obvious that the battery acts as a hard source. Short-term stress is followed by a sharp drop in voltage, which corresponds to the discharge characteristics of these battery types.

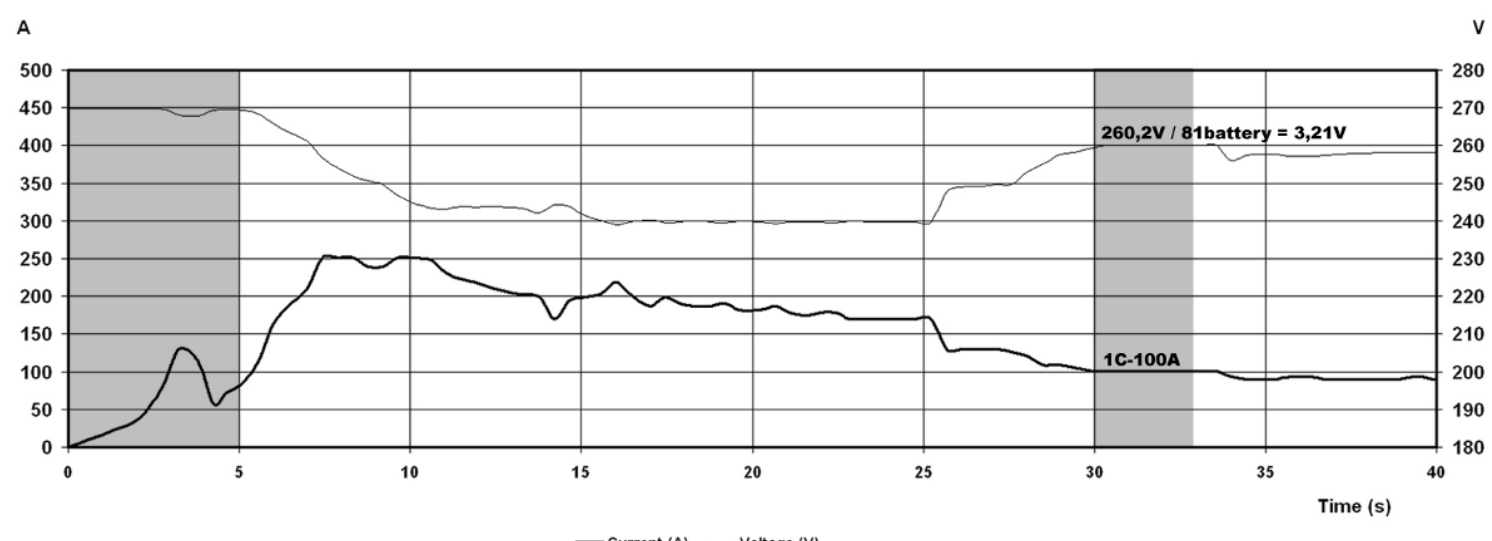

Figure 9: Comparison of voltage and current.

If we focus on the specific voltage decrease with the current of 1C (100A), which is visible on the graph (over 30 seconds), the value is $260.2 \mathrm{~V}$. If we calculate the total pack voltage for a single cell, i.e. 260.2 / $81=3.21 \mathrm{~V}$, we obtain a value which corresponds to the discharge characteristics shown in Figure 10 (manufacturer's parameters) (ThunderSky, 
2007). The cell's voltage, with Discharge Capacity ranging from 0 to $60 \%$ in this graph, is at about the same level. Through this analysis, we verified the correct function and behaviour of the battery under load, as well as the accuracy of the measurement through Controller Monitor. The manufacturer's graph shows a sharp drop in voltage with a Discharge Capacity of $100 \%$. The battery is not used anymore at this level. Voltage below the allowed limit of $2.8 \mathrm{~V}$ leads to irreversible changes, which have a negative effect on the subsequent capacity and current load of the cell.

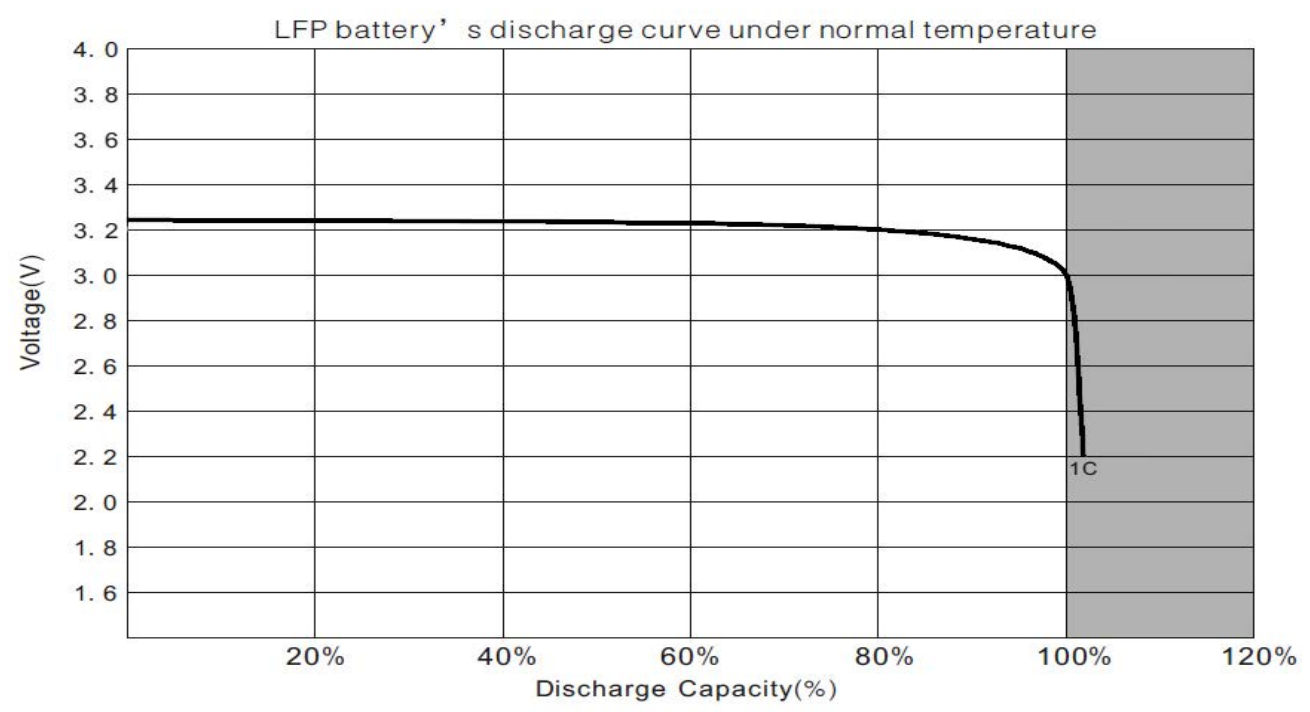

Figure 10: ThunderSky LFP battery discharge curve (ThunderSky, 2007).

Another measuring device developed by DVMT as part of the ExperimentalCar CZ.1.07/2.2.00/07.0060 project measures the dynamic and static acceleration in three mutually perpendicular axes. Figure 11 . shows a scan of the program analysing vibration on the vehicle. The program measures acceleration in real time and enables signal filtering, as well as the frequency analysis of the measured values. At the same time, it is able to save the measured data for further processing.

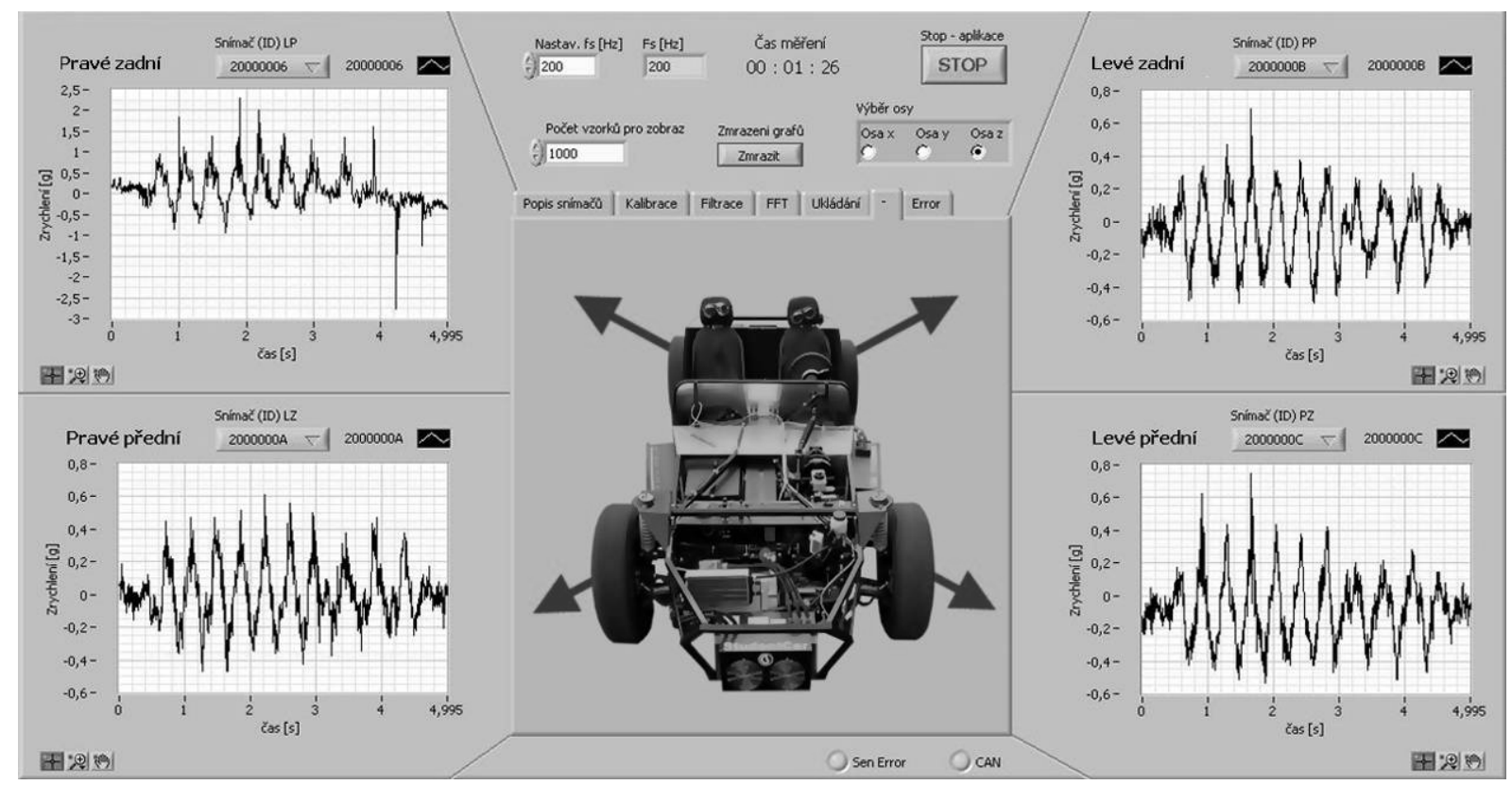

Figure 11: Vibration analyser. 


\section{RESULTS AND DISCUSSION}

The above mentioned measurement possibilities and achievements enabled a complex mapping of the electric car's operating conditions. As a result, we can better develop scientific and developmental activities in the area of the functional units' optimisation. Diverse measurement options also significantly speed up the development of electromobility and vehicle construction.

Based on the measurements, we obtained the data and parameters necessary for a detailed simulation of the boundary conditions of a partial construction point. The data mainly concerns the acceleration of the wheels (axle) and the load on the respective frame parts. We use this information as input data, and, based on this information, we derive boundary conditions for the given type of construction. The subsequent simulation is carried out in the SIMPACK and ANSYS programs. This significantly enhances the quality, as well as the faster and cheaper development, of each new prototype created at DVMT.

The results of the operating quantities measurement using the Controller Monitor program influenced the subsequent dimensioning of batteries with regard to the range and performance of the electric car. Information about the electric car's consumption at different loads was particularly useful.

These advanced activities created conditions for a new project, under which DVMT is developing a totally unique type of an electric car.

The above mentioned activities of DVMT constitute only a small part of the institute's portfolio. They map the institute‘s rapid development over the past two years.

The results were achieved thanks to the financial support provided for the project CZ.1.07/1.1.07/11.0109.

\section{REFERENCES}

Čech, R., Buřval, L., Klaus, P., 2011. Measuring the Electric Strength of Board Composite Materials and Insulators. Transactions on transport science, vol. 4, no. 1, pp. 19-24. ISSN 1802-971X.

Macur, J., 2011. Alternativní pohony v dopravě: Technická, ekologická a sociální analýza [online]. Asociace elektromobilového průmyslu. [cit. 2011-11-03]. Retrieved from: www.elektromobily.org/w/images/6/66/AltPohVDopr.ppt (in Czech)

Plichta, V., 2008. Bohatší vybavení automobilů působí proti redukci jejich hmotnosti. Technik [online]. [cit. 2011-11-03]. Retrieved from: http://technik.ihned.cz/c1-28859510-bohatsivybaveni-automobilu-pusobi-proti-redukci-jejich-hmotnosti (in Czech)

ThunderSky, 2007. ThunderSky: Lithium Battery [online]. [cit. 2011-11-11]. Retrieved from: http://www.everspring.net/TS-LFP100AHA.pdf 